Research Article

\title{
ASSESSMENT OF QUALITY CHARACTERISTICS OF BOILED YAM TUBERS AVAILABLE IN BANGLADESH
}

\author{
F.N. Jahan ${ }^{1 *}$, M.A. Rahim ${ }^{1}$, M.M. Hossain ${ }^{1}$, M.H. Rahman ${ }^{1}$ \\ M.A.Z. Chowdhury ${ }^{2}$, M. Moniruzzaman ${ }^{1}$ and A.K. Samanta ${ }^{3}$ \\ ${ }^{1}$ Department of Horticulture, Bangladesh Agricultural University, Mymensingh, Bangladesh \\ ${ }^{2}$ Bangladesh Agricultural Research Council, Farmgate, Dhaka \\ ${ }^{3}$ SAARC Agriculture Centre, BARC Complex, Farmgate, Dhaka
}

\begin{abstract}
Tuber of yam (Dioscorea spp.) is one of the important foods widely popular in several countries. In spite of its assignment in the category of underutilized crop, the tubers of yam are consumed by the people of Bangladesh in different forms. The current paper has made an endeavor to evaluate the sensory qualities of boiled yam tubers by the panel of evaluators. The quality parameters that were considered for evaluation of boiled yam tubers were ease of peeling, poundability, discoloration of water after boiling, color and texture, bitterness, sweetness, etc. Evidently, it was possible to judge the quality of yams based on the sensory evaluation as it is one of the important steps for acceptability of foods and their subsequent usages. Around 31 tuber samples were harvested during the winter season from the Germplasm Centre of Bangladesh Agricultural University. Amongst the 31 samples, 24 came under the category of 'easy to peel', and 'difficult to peel' were only 7 samples. Regarding the color after cooking, 19 samples were "white, not colored", whereas, 3 samples were intermediate and 9 samples were highly colored; might be attributed by the presence of phyto-compounds. Nevertheless, two samples i.e. RHMF002 and RMHF010 were found to possess most of the favorable sensory characters in terms of discoloration of water after boiling, sweetness, bitterness, texture, poundability, etc.
\end{abstract}

Keywords: Yam, Tuber, Sensory evaluation, Quality characteristics

\section{INTRODUCTION}

The yams have received limited attention among the global researchers during the past leading to its placement under the category of neglected/ underutilized/ orphan

* Corresponding author: nimmy_301@yahoo.com 
crops. The word "Yam" is applicable to the members of the genus Dioscorea, family Dioscoreaceae, and the order Dioscoreales (Alexander and Coursey, 1969).According to the available historical evidence, Pedanius Dioscorides, the Greek physician cum botanist, quoted the application of yams as food as well as medicines in his book entitled "De Materia Medica", written during the period AD 50 and 70. In order to honor the outstanding thoughts of the great Greek botanist, the genus name of the yam has been assigned as Dioscorea and the family name as Dioscoreaceae. The popular name "yam" has been originated from the West African language - "nyami" means "to eat" (Coursey, 1976). The family Dioscoreaceae is believed to be the one among the earliest angiosperms, and is probably originated from Southeast Asia (Coursey, 1967). In Bangladesh, the yam is considered as one kind of alu (means potato) and therefore termed with different names such as "GachAlu", "PestaAlu", "MouAlu", "GointaAlu", "PaglaAlu", "Sore Alu" (Alam et al., 2008).

The growth of yams appears to have developed independently in two regions: West Africa and Southeast Asia. According to the available reports, Dioscorea rotundata thought to be the first species that has been domesticated around $5000 \mathrm{BC}$ in West Africa (Andres et al., 2017). The most economically important species under this genus is D. alata, that is originated from Southeast Asia; possibly Myanmar and Thailand (Orkwor et al., 1998). Presently, the species of Dioscorea are distributed among Malaysia, Indonesia, Philippines, Brazil, South America, Central America, Papua New Guinea, South Pacific Islands (Kumar et al., 2017). Air potato i.e. D. bulbifera is native to South Asia and is distributed among several countries such as Bangladesh, India, China, Cambodia, Indonesia, Java, Japan, Laos, Malaysia, Nepal, Pakistan, Sri Lanka, Thailand, Taiwan, Vietnam, Ghana, Gabon, Congo, Chad, Cameroon, Nigeria, Senegal, Sudan, Zimbabwe, USA, Mexico, Cuba, Costa Rica, Jamaica, Nicaragua, Brazil, Ecuador, Peru, Venezuela, Australia, etc. The other high yielding species is $D$. pentaphylla, a native of tropical Asia (Ayensu and Coursey, 1972). It is found in India, Bangladesh, North America, and other tropical Asian nations.

In fact, the yams (Dioscorea spp.) are perennial herbaceous vines cultivated for the consumption of their starchy tubers in Asia, Africa, Central and South America, and Oceania (Liu et al., 2008). It is the fourth largest source of carbohydrates (immediately after potatoes, cassava, sweet potato) in the category of roots and tubers which meet the energy requirement of millions of global populations in addition to its role as important ingredients as animal feed and numerous processed products for human consumption (Pradhan and Panda, 2020; Viruel et al., 2015). Even though, Dioscorea spp. is an underutilized crop, yet it is found almost all over Bangladesh and its tubers are primarily used as vegetable (Alam et al., 2008). Besides the presence of carbohydrates and essential minerals, the yam tubers are thought to be the rich source of nutraceuticals; indispensable for good health and well-being of mankind (Jahan et al., 2019). The notable feature of yam is that it could be cultivated at the roadside, homestead gardens, backyards, rooftops in addition to its natural 
occurrence in the forest. Hence, no extra cultivable land needs to be spared for yam cultivation like other root and tuber crops. Besides, different ethnic groups also grow the yam at the foothills of Bangladesh. In Bangladesh, it is routinely taken along with meat, fish, green vegetables, coconut, and spices, depending on the individual's preference (Alam et al. 2008). As on date, there is frugal information available on the quality characteristics of yam tubers available in Bangladesh. Keeping in view the above perspectives, the current research was aimed to evaluate the sensory characteristic features of boiled yam tubers based on standard criteria.

\section{MATERIALS AND METHODS}

The BAU-Germplasm Centre of Bangladesh Agricultural University, Mymensingh is maintaining the germplasms of different Dioscorea spp. The tubers (thirty-one) of the yam were harvested during December 2019 and subjected to sensory evaluation under the similar conditions and methods on the same day (Ojokoh and Adeleke, 2019). The mature tubers were carefully selected and thoroughly washed by potable tap water to get rid of soil and extraneous material before peeling with sharp stainless-steel knives. The peels were removed and washed once again with potable water. The peeled yam tuber was sliced into uniform pieces of 15 to $20 \mathrm{~g}$ each. Approximately, 12- 14 pieces of yam tubers were cooked in water till its softening. After completion of cooking, water was drained out and pieces of tubers were placed over the plates for sensory evaluation by ten random panelists from the staff of the university based on their willingness to participate (IPGRI/IITA, 1997). The following quality characteristics were considered towards the sensory evaluation of yam tubers: (i) ease of peeling (1: difficult, 2: easy, 3: usually eaten unpeeled), (ii) poundability of boiled tuber (1: poor, 2: good), (iii) cooking time to softness (min), (iv) discoloration of cooking water (1: very low, 5: Intermediate, 9: very high), (v) color of tuber after cooking (1: white, not colored, 5: intermediate, 9: highly colored), (vi) texture of cooked tuber (1: smooth, 2: grainy, 3: fibrous), (vii) bitterness of cooked tuber ( 0 : not bitter, 1: bitter, 2: very bitter), (viii) sweetness of cooked tuber (0: not sweet, 1: sweet, 2 : very sweet), (ix) overall assessment of cooked tubers (3: low, 5: intermediate, 7 : high).

\section{RESULTS AND DISCUSSION}

With the ever-growing human population coupled with the fast depletion of natural resources, it is very imminent to diversify the present-day agriculture production system to meet the various needs of the people under changing lifestyle (Janardhan et al., 2003; Jahan et al., 2019; Shajeela et al., 2011). In that course of challenging action, Dioscorea spp. occupy significant niche because its tubers and bulbils could be used for regular food as well as for production of numerous pharmaceutical products of higher economic significance (Liu et al., 2008; Viruel et al., 2015). Albeit, the impression of food consumed by different group of people varies, nevertheless, the consumer often prefers to choose certain edible foods based on parameters relied on sensory analysis (Amare, 2016). Therefore, the current research was performed in order to evaluate the sensory quality characteristics of boiled yam tubers. The quality characteristics of boiled yam tubers are presented in Table 1. 
Table 1: Sensory characteristics of boiled tubers originated from Dioscorea spp.

\begin{tabular}{|c|c|c|c|c|c|c|c|c|c|}
\hline $\begin{array}{c}\text { Accession } \\
\text { No. }\end{array}$ & $\begin{array}{l}\text { Ease of } \\
\text { peeling }\end{array}$ & $\begin{array}{l}\text { Poundabil } \\
\text { ity of } \\
\text { boiled } \\
\text { tuber }\end{array}$ & $\begin{array}{l}\text { Cooking } \\
\text { time to } \\
\text { softness } \\
\text { (min) }\end{array}$ & $\begin{array}{l}\text { Dis- } \\
\text { coloration of } \\
\text { cooking } \\
\text { water }\end{array}$ & $\begin{array}{l}\text { Color of } \\
\text { cooked } \\
\text { tuber after } \\
\text { cooking }\end{array}$ & $\begin{array}{l}\text { texture of } \\
\text { cooked } \\
\text { tuber }\end{array}$ & $\begin{array}{l}\text { bitterness of } \\
\text { cooked } \\
\text { tuber }\end{array}$ & $\begin{array}{l}\text { sweetness } \\
\text { of cooked } \\
\text { tuber }\end{array}$ & $\begin{array}{l}\text { overall } \\
\text { assessment of } \\
\text { cooked tubers }\end{array}$ \\
\hline RMHF001 & 2 & 2 & 25 & 9 & 1 & 3 & 0 & 1 & 7 \\
\hline RHMF002 & 2 & 2 & 15 & 1 & 1 & 1 & 0 & 2 & 7 \\
\hline RHMF003 & 1 & 1 & 30 & 9 & 9 & 3 & 1 & 0 & 3 \\
\hline RMHF005 & 2 & 2 & 20 & 5 & 9 & 1 & 0 & 0 & 5 \\
\hline RMHF006 & 2 & 1 & 30 & 9 & 9 & 3 & 1 & 0 & 3 \\
\hline RMHF007 & 2 & 2 & 20 & 9 & 5 & 1 & 0 & 1 & 5 \\
\hline RMHF008 & 1 & 1 & 25 & 1 & 5 & 3 & 2 & 0 & 3 \\
\hline RMHF012 & 2 & 1 & 45 & 9 & 9 & 3 & 1 & 0 & 3 \\
\hline RMHF013 & 2 & 2 & 10 & 1 & 1 & 1 & 0 & 1 & 5 \\
\hline RMHF014 & 2 & 2 & 10 & 1 & 1 & 2 & 0 & 0 & 5 \\
\hline RMHF015 & 1 & 1 & 50 & 9 & 9 & 2 & 0 & 0 & 5 \\
\hline RHMF016 & 2 & 2 & 20 & 1 & 1 & 2 & 0 & 0 & 7 \\
\hline RHMF017 & 2 & 2 & 20 & 1 & 1 & 2 & 0 & 1 & 7 \\
\hline RHMF018 & 2 & 2 & 20 & 1 & 1 & 2 & 0 & 1 & 7 \\
\hline RHMF019 & 2 & 2 & 20 & 1 & 1 & 2 & 0 & 1 & 7 \\
\hline
\end{tabular}




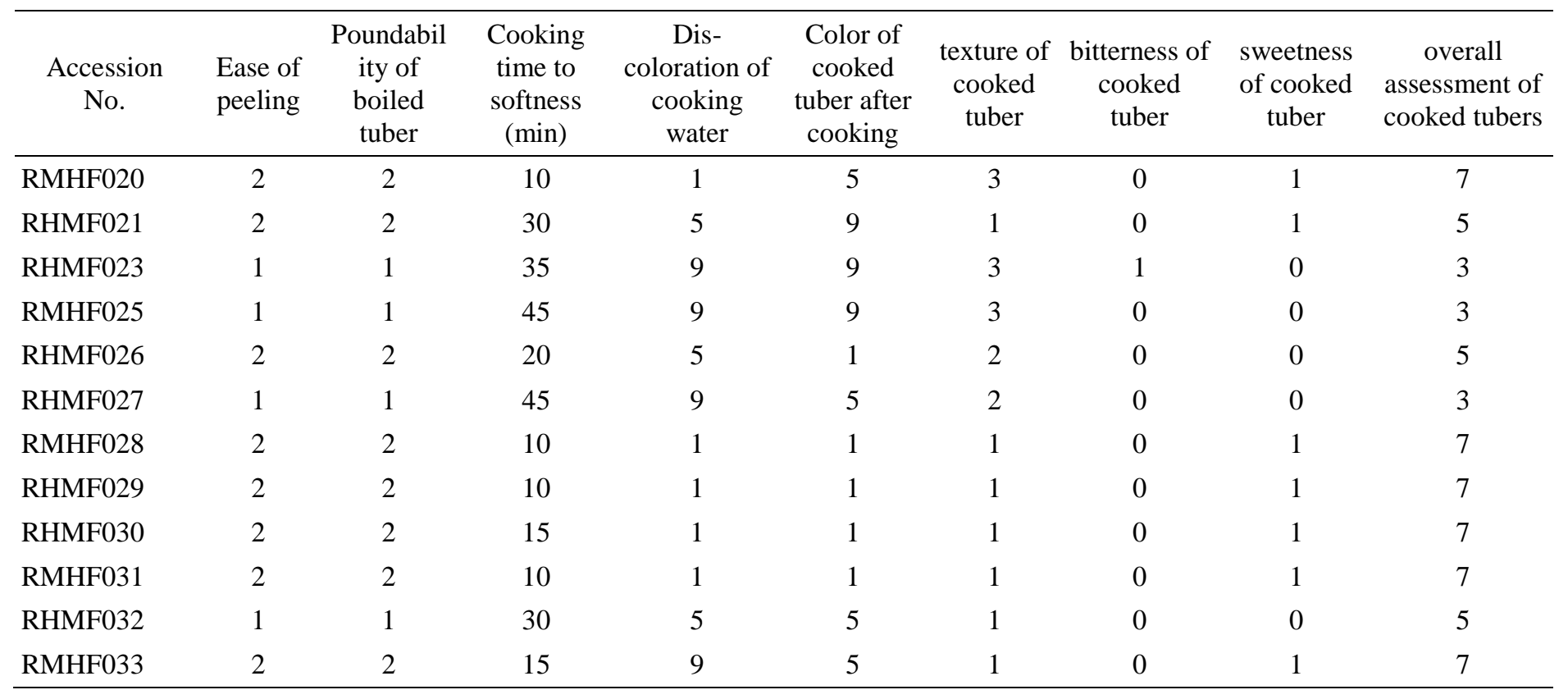

Ease of peeling (1: difficult, 2: easy, 3: usually eaten unpeeled), (ii) poundability of boiled tuber (1: poor, 2: good), (iii) cooking time to softness (min), (iv) discoloration of cooking water (1: very low, 5: Intermediate, 9: very high), (v) color of tuber after cooking (1: white, not colored, 5: Intermediate, 9: highly colored), (vi) texture of cooked tuber (1: smooth, 2: grainy, 3: fibrous), (vii) bitterness of cooked tuber (0: not bitter, 1: bitter, 2: very bitter), (viii) sweetness of cooked tuber (0: not sweet, 1: sweet, 2: very sweet), (ix) overall assessment of cooked tubers (3: low, 5: intermediate, 7 : high) 
The first step of utilizing food is assessed based on its ease of peeling. This step was carried out by the team members of the current research. According to this criteria, 7 samples were found to be in category 1 i.e. difficult, while rest 24 samples were in category 2 i.e. easy to peel. As poundability (mealiness) is one of the important principles for the evaluation of tubers and roots, the present research assessed the particular parameter by the panel of evaluators of all the collected samples after boiling. Evidently, 11 samples were poor in terms of poundability, while rests 20 were of good standing. The cooking time to softness varied from 10 to $50 \mathrm{~min}$ among the different samples; being lowest in RMHF010, RMHF013, RMHF014, RMHF020, RMHF028, RMHF029, and RMHF031 whereas highest in RMHF009 and RMHF015. The color of tubers is the function of phytochemicals present and it is considered as one of the most important features for its acceptability and attractiveness as a food item. During boiling, part of those phytochemicals comes out of tuber and changes the color of boiling water and the remaining fraction is responsible for the appearance of the boiled tuber. This study revealed all three categories for the specific attribute i.e. "discoloration of cooking water" (Fig. 1). Nevertheless, 13 samples belonged to very low (1), while 5 samples were in the intermediate (5) rank, and rest 13 samples were of the very high category (9). Obviously, the appearance of cooked yam tuber having white color (Fig. 2) is preferred as it will not alter the final color of dishes or food preparations owing to its mere presence. In the perspectives of "color of cooked tuber after cooking", the current research recorded 15, 7 and 9 number of samples in the category of "white, not colored", "intermediate" and "highly colored," respectively. The texture of the cooked tubers (smooth, grainy, or fibrous) depends upon the presence of starch and its proportion along with other nutrients. The different kinds of texture of boiled yam noticed in the current investigation are presented in Fig. 3. Out of the 31 samples of boiled yam, qualities of 12 were smooth, 10 were grainy and rests 9 were fiber type.

Bitterness is the attribute of tuber which is resulted by the presence of bitter principles in the form of phenolics or other compounds. According to the taste panels, no bitter taste was found in 25 samples, while 5 samples were medium in bitter and one sample was identified as very bitter (RMHF008). Among all the tested samples of yam, 2 samples were very sweet (RMHF002 and RMHF010), 14 samples were moderately sweet, and rest 15 belonged to the category of 0 i.e. not sweet. In the perspectives of the overall assessment of the cooked tubers of yam, 14 were adjudged in the rank of "high", 9 were ranked as intermediate, and rest 8 samples were considered as 'low category'. 

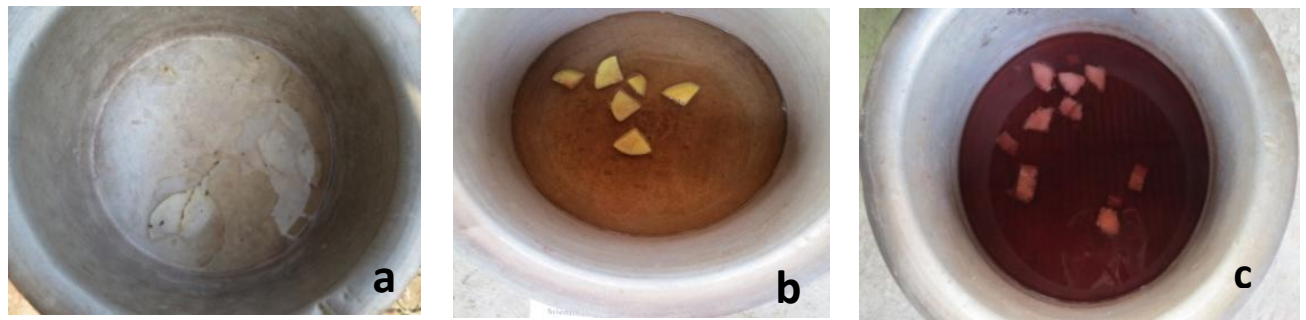

Figure 1. Discoloration of cooking water; a: very low, b: intermediate, c: very high
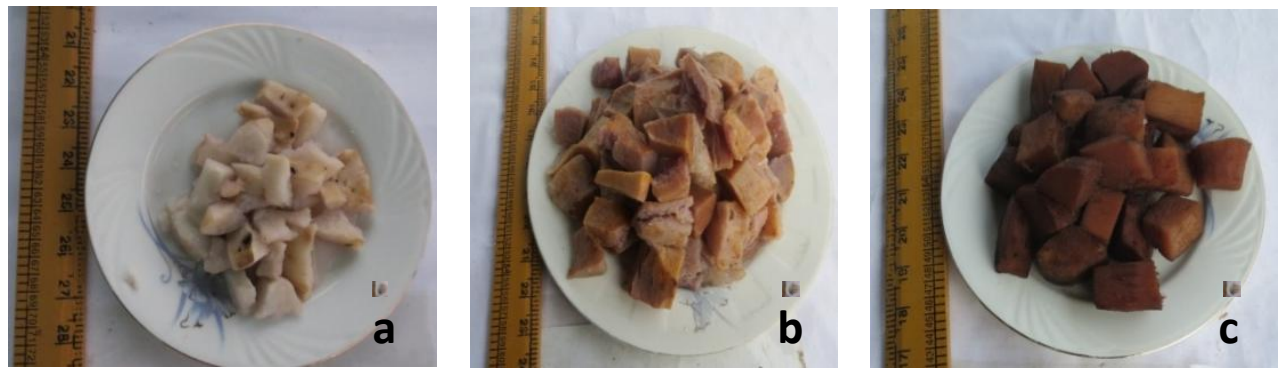

Figure 2. Color of yam tubers after boiling; a: white, not colored, b: intermediate color and c: highly colored
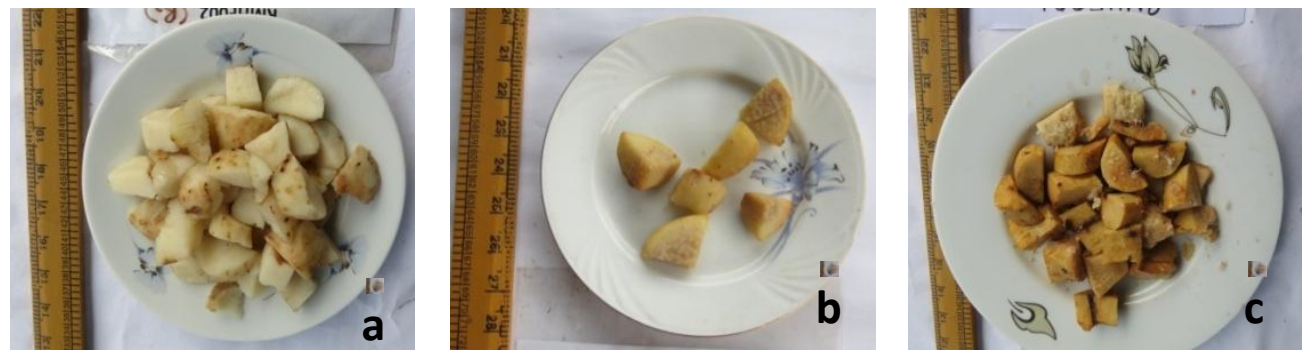

Figure 3. Texture of cooked tuber; a: smooth, b: grainy and c: fibrous

In the promotion of any food crops, sensory evaluation is not only the most important step but also a major determinant for acceptability of the particular variety and its subsequent adoption and usages by the farming communities (Jeannette et al., 2020). The analysis of sensory quality represents a group of physical characteristics that derive from the perceived structure of the food by different sense organs (Kohyama, 2020). The main factors of consumers' acceptability of any food crops depend upon its ease of cleaning, color, texture, tenderness, elasticity, attractiveness, taste, etc.

The current research made an endeavor to perform sensory evaluation of boiled tubers of different yam obtained from the BAU-Germplasm Collection Centre, Bangladesh Agricultural University after following the standard evaluation criteria 
(IPGRI/IITA, 1997). The study was successful to distinguish the different samples based on the quality parameters of cooked tubers. In fact, boiling in water is routinely practiced to evaluate the quality of roots and tubers (Amare, 2016). The tubers of yam could be consumed in different forms, mainly boiled, roasted, grilled or fried, and served sliced, as balls, mashed, chipped or flake (Kapsiya et al., 2015). In some cases, the boiled yam is pounded and consumed with sauce or stew. The tubers of yam are peeled, chipped, dried and milled into flours to make numerous products of choice in different parts of the world. Recently, sensory evaluation of boiled and pounded form of yam has been successfully used in varietal improvement scheme of Dioscorea spp. (Jeannette et al., 2020). The current research outlined the characteristics of the boiled tubers of 31 samples available in Bangladesh. Amongst the tested samples, two (RHMF002 and RMHF010) were found to be superior as compared to the rest 29 samples in view of sensory evaluation criteria especially ease of peeling, poundability, discoloration of water after cooking, color of tuber after cooking, texture of the cooked tuber, bitterness of cooked tuber, sweetness of cooked tuber and overall assessment. However, evaluation of nutritional attributes coupled with medicinal values should be explored for justifying its future course of actions particularly breed improvement, packages of practices, product diversification and varietal release in order to uphold the principles of biodiversity vis a vis food security of indigenous people.

\section{CONCLUSION}

The current research made an effort to undertake the sensory evaluation of 31tuber samples of yam after boiling in water. Evidently, differences in the sensory qualities in terms of ease of peeling, poundability, color and texture of tubers, sweetness or bitterness were noticed among the samples. Among the 31 tested samples, two (RHMF002 and RMHF010) were found to be superior in most of the sensory evaluation parameters particularly ease of peeling, poundability, discoloration of water after cooking, color of tuber after cooking, taste (either bitter or sweet) and overall assessment. Intensive research is imminent for justifying those sensory characteristics of the yam tuber samples with the application of advanced tools.

\section{REFERENCES}

Alam, M.S., Bhuiyan, M.K.R., Hossain, M. and Begum, S.N. (2008). Improved production technology of yam (in Bangla). Technical bulletin published by Tuber Crops Research Centre, Bangladesh Agricultural Research Institute (BARI), Joydebpur, Gazipur. Pp. 1-8.

Alexander, J. and Coursey, D.G. (1969). The origins of yam cultivation in the domestication and exploitation of plants and animals. Proceedings of a meeting of the research seminar in archaeology and related subjects held at the Institute of Archaeology, London University. Gerald: Duckworth \& Co. Ltd. Pp. 405 - 425

Amare, A. (2016). Analysis of sensory and texture properties of three potato cultivars boiled to different thermal center temperatures. MSc thesis. Department of Food Technology, Lund University, Lund, Sweden. 
Andres, C., Adeoluwa, O. and Bhullar, G.S. (2017). Yam (Dioscorea spp.). Encyclopedia of Applied Plant Sciences. Vol. 3, Waltham, MA. Academic Press. Pp. 435 - 441.

Ayensu, E.S. and Coursey, D.G. (1972). Guinea yams: the botany, ethnobotany, use and possible future of yams in West Africa. Economic Botany. 26: 301-318

Coursey, D.G. (1967). Yams: An Account of the Nature, Origins, Cultivation and Utilization of the Useful Members of the Dioscoreaceae. London: Longmans, Greens and Co. Ltd.

Coursey, D.G. (1976). The origins and domestication of yams in Africa. In: Origin of African plant domestication (eds Harlan, J.R., De Wet, J.M.J.), Stemler Mouton A.B.L. Publishers, Hague, the Netherlands. Pp. 383 - 408

IPGRI/IITA. 1997. Descriptors for yam (Dioscorea spp.). International Institute of Tropical Agriculture, Ibadan, Nigeria/International Plant Genetic Resources Institute, Rome, Italy. Pp. 1-53

Jahan, F.N., Rahim, M.A., Bokhtiar, S.M. and Samanta, A.K. (2019). Potentiality of underutilized crop Dioscorea spp.: A source of nutraceuticals. SAARC Journal of Agriculture. 17(2): 1-13

Janardhanan, K., Vadivel, V. and Pugalenti, M. (2003). Biodiversity in Indian underexploited/tribal pulses. In: Improvement Strategies for Leguminosae Biotechnology (edited by P.K. Jaiwal and R.P. Singh). Kluwer Academic Publishers. Printed in Great Britain. Pp. 353 - 405.

Jeannette, F., Faouziath, S., Estelle, L.Y.L., Celestin, T., Cartney, I.C., Innocent, B.Y. and Alexandre, D.A. (2020). Sensory evaluation and consumers acceptability of some yam (Dioscorea rotundata) cultivars used as parents in a yam varietal development program in Benin. International Journal of Current Microbiology and Applied Sciences. 9(3): 2083-2100.

Kapsiya, J., Gungula, D.T., Tame, V.T. and Abakura, J.B. (2015). Effects of different concentrations of chemical sprout inhibitors on the sensory evaluation and food composition of stored yam (Dioscorea rotundata Poir) Tubers. American Journal of Agricultural Science. 2(5): 189-195.

Kohyama, K. (2020). Food Texture - sensory evaluation and instrumental measurement. In: Textural characteristic of world foods (edited by Katsuyoshi Nishinari). Published by John Wiley \& Sons Ltd. Pp. 1-13..

Kumar, S., Das, G., Shin, H.S. and Patra, J.K. (2017). Dioscorea spp. (a wild edible tuber): a study on its ethnopharmacological potential and traditional use by the local people of Simplipal biosphere reserve, India. Frontiers in Pharmacology. 8:52

Liu, Y.W., Shang, H.F., Wang, C.K., Hsu, F.L. and Hou, W.C. (2007). Immunomodulatory activity of dioscorin, the storage protein of yam (Dioscorea alata cv. Tainong No. 1) tuber. Food Chemistry and Toxicology.45: 2312- 2318.

Ojokoh A. and Adeleke B. (2019). Processing of Yam Paste (Amala): A Product of Fermented Yam (Dioscorea rotundata) Flour. International Annals of Science. 8(1): 87-95. 
Orkwor, G.C., Asiedu, R. and Ekanayaka, I.J. (1998). Food Yams: Advances in Research. Ibadan: International Institute of Tropical Agriculture/NRCRI.

Pradhan, B. and Panda, D. (2020). Potential of neglected and underutilized yams (Dioscorea spp.) for improving nutritional security and health benefits. Frontiers in Pharmacology.11:496.

Shajeela, P.S., Mohan, V.R., Jesudas, L.L. and Soris, P.T. (2011). Nutritional and antinutritional evaluation of wild yam (Dioscorea spp.). Tropical and Subtropical Agroecosystem. 14:723-730.

Viruel, J., Segarra-Moragues, J.G., Raz, L., Forest, F., Wilkin, P., Sanmartin, I. and Catalan, P. (2015). Late cretaceous-early Eocene origin of yams (Dioscorea, Diocsoreaceae) in the laurasianpalaearctic and their subsequent oligocene-miocene diversification. Journal of Biogeography. 43(4): 760 -76. 